\title{
Mediyal menisküs transplantasyonu
}

\author{
Medial meniscus transplantation
}

\author{
Mustafa Akkaya, Murat Bozkurt
}

Ankara Yıldırım Beyazıt Üniversitesi Tıp Fakültesi, Ortopedi ve Travmatoloji Anabilim Dalı, Ankara

\begin{abstract}
Onarımı mümkün olmayan menisküs yırtıklarının tedavisinde, total ya da subtotal menisektomi sıklıkla uygulanabilmektedir. Bu tür hastalarda, ilerleyen yıllar içinde diz ekleminde biyomekanik bozulma ve fonksiyonel hasar gelişmektedir. Bu durumu düzeltmek adına uygulanabilecek en yüz güldürücü tedavi, menisküs allogreft transplantasyonu olarak görülmektedir. Seçim kriterlerine uygun olarak belirlenen hastalara, tecrübeli cerrahlar tarafindan gerçekleştirilen transplantasyon ile, kısa, orta ve uzun dönem sonuçlar oldukça başarılı olarak raporlanmıştır. Menisküs transplantasyonu cerrahi teknik olarak mediyal ve lateral kompartmanda farklılıklar içermekte olup, bu makalede mediyal menisküs transplantasyonuna ait anatomik tanımlar, endikasyonlar, cerrahi teknik ve rehabilitasyondan bahsedilecektir.
\end{abstract}

Anahtar sözcükler: diz; mediyal menisküs; allogreft transplantasyonu
Total or subtotal menisectomy can often be applied in the treatment of meniscal tears, which can not be repaired. In these types of diseases, biomechanical deterioration and functional damage develops in the knee joint over the years. Allograft transplantation is considered the most satisfactory treatment that can be performed to correct this condition. Short, medium, and long term outcomes with transplantation performed by experien-ced surgeons determined according to selection criteria have been reported to be very successful. Meniscus transplantation is a surgical technique that involves differences in the medial and lateral compartments. Anatomical definitions, indications, surgical technique, and rehabilitation of the medial meniscus transplantation will be mentioned in this article.

Key words: knee; medial meniscus; allograft transplantation

tutunur. Periferik kenarları eklem kapsülüne sıkıca yapışmışken, koroner bağlar aracılı̆̆ı ile de tibia üst yüzeyine sıkıca tutunmuştur. Arka boynuzunun yüzeyi ön boynuzundan geniştir (Şekil 1).

\section{BIYOMEKANIK}

Menisküslerin anatomik lokalizasyonları ve visko-elastik özellikleri, biyomekanik görevlerinin belirleyicisidir. Bu özellikleri sayesinde diz ekleminde birçok önemli işlev üstlenirler. Bunların başında ise yüklenme sırasında diz ekleminde yükü eşit olarak dağıtmak düşünülebilir. Çeşitli biyomekanik çalışmalar, diz eklemine gelen tüm yükün \%50'sini mediyal menisküsün, \%70'ini ise lateral menisküsün taşıdığını göstermektedir. ${ }^{[2,3]}$

Diz hareketleri sırasında ekleme gelen yüklerin ekstansiyonda \%50'sini; fleksiyonda ise \%85'ini

- İletişim adresi: Prof. Dr. Murat Bozkurt, Ankara Yıldırım Beyazıt Üniversitesi, Ortopedi ve Travmatoloji Anabilim Dalı, 06800 Ankara, Türkiye Tel: 0312 - 2912525 / 4764 e-posta: nmbozkurt@gmail.com

- Geliș tarihi: 1 Mart $2018 \quad$ Kabul tarihi: 1 Mart 2018 


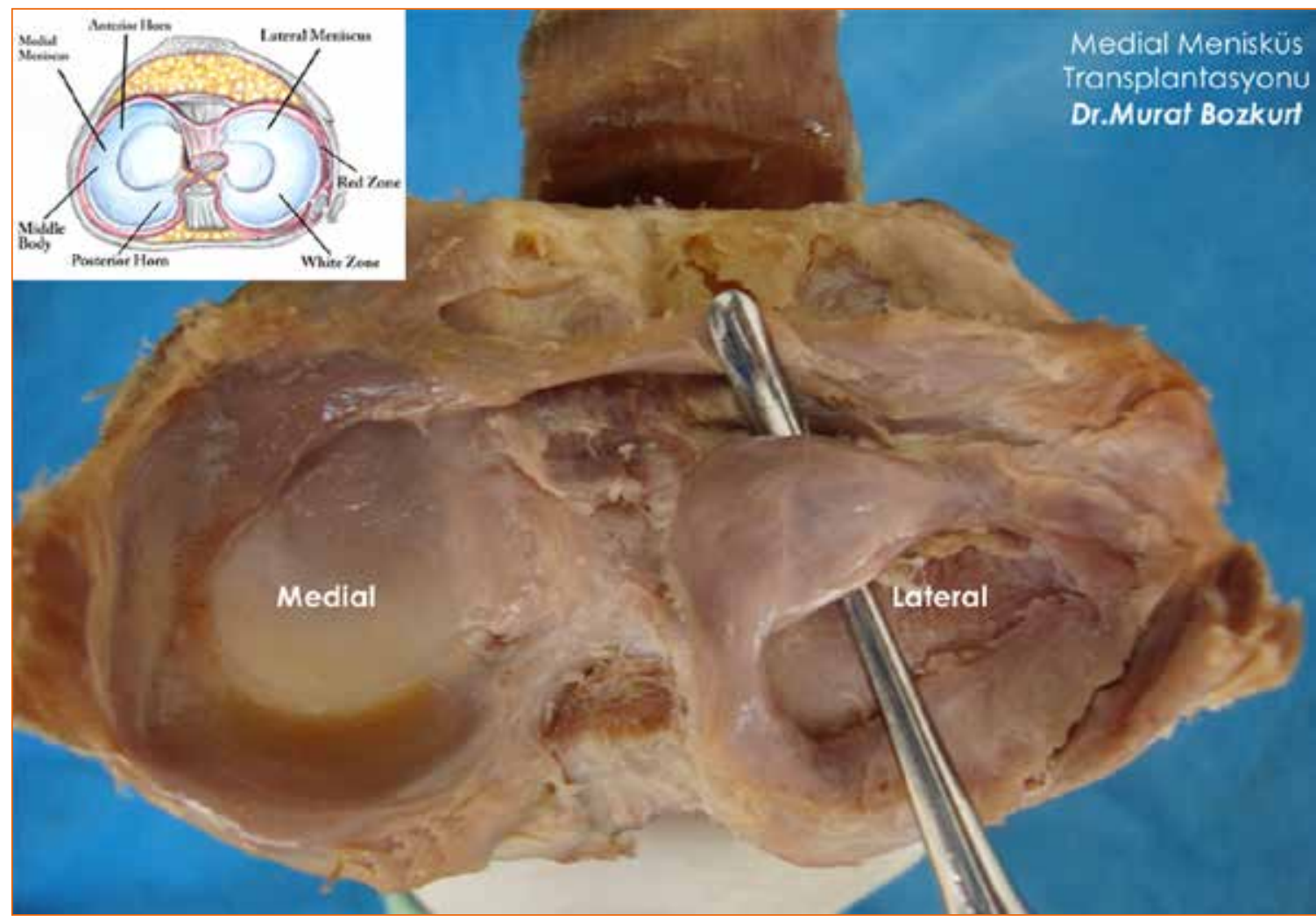

Şekil 1. Mediyal ve lateral menisküsün kadavra disseksiyonu sonrası görüntüsü.

menisküsler taşımaktadır. Mediyal menisküsün $1 / 3$ iç kısmına yapılan parsiyel menisektomi sonrası, temas alanı $\% 10$ azalır ve menisküs üzerindeki yüklenme \%65 artar. Total mediyal menisektomi sonrası temas alanı $\% 75$ azalmakta ve menisküs yüklenmesi \%235 artmaktadır. ${ }^{[4,5]}$

Menisküsler, ayrıca dizin stabilizasyonunda da görev almaktadır. Mediyal menisküsün arka boynuzu, ÖÇB yaralanması geçirmiş bir dizde ikincil stabilizatör olarak görev alır. Allen ve ark. tarafından yapılan bir çalışmada, ÖÇB'si yırtık olan bir dizde, mediyal menisküs üzerinde ortaya çıkan gerilme gücünün sağlam dize göre anlamlı derecede yüksek olduğu gösterilmiştir. ${ }^{[6]}$

Menisküslerin diğer önemli görevleri arasında ise diz propriyosepsiyonu ve eklem lubrikasyonu gelmektedir. ${ }^{[7,8]}$

\section{CERRAHI ENDIKASYONLAR VE KONTRENDIKASYONLAR}

Eklem içi menisküs defektlerinin gelişimi, kontakt temas alanın azalmasına ve artan eklem içi temas basıncı sebebiyle kıkırdak hasarı gelişimine sebep olur. Bu durum, ilerleyen dönemlerde eklem dejenerasyonu ve osteoartrit gelişimine sebep olur.

$\mathrm{Bu}$ nedenle, uygulanacak menisküs allogreft transplantasyonu ile eklem içi anatomi düzeltilmeye ve eklem içi fonksiyonlar doğal haline getirilmeye çalışılır. ${ }^{[9,10]}$

\section{Endikasyonlar}

Menisküs allogreft trasplantasyonu için uygun cerrahi endikasyonları inceleyecek olursak, şu şekilde sıralayabiliriz:

1. Menisküs defektinin bulunduğu kompartmanda ağrı.

2. Stabil bir diz eklemi.

3. Dizilim bozukluğu bulunmaması.

4. Eklem kıkırdak dejenerasyonunun ICRS (International Cartilage Repair Society) sistemine göre Evre 3'ten fazla olmaması.

Hastaların eşlik eden ÖÇB yırtıklarının da bulunması durumunda, aynı seansta ÖÇB rekonstrüksiyonu uygulanarak, hem stabil bir diz eklemi hem de mediyal menisküs allogreftinin stabilitesi arttırılarak korunması sağlanabilir. Bu sayede daha fonksiyonel bir allogreft transplantasyonu gerçekleştirilmiş olur. ${ }^{[11]}$ 


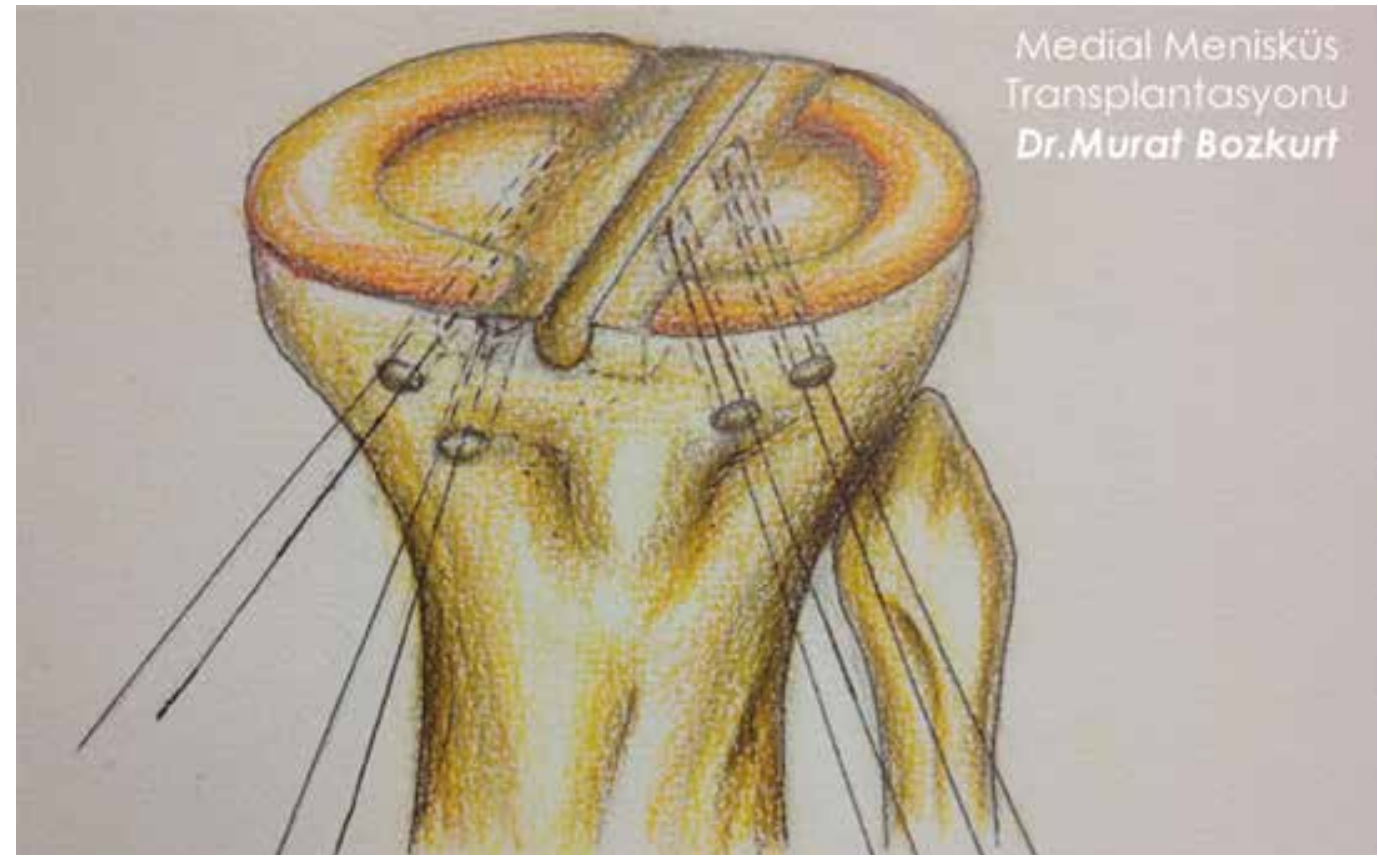

Şekil 2. Menisküs allogreft transplantasyonu sırasında kullanılan kemik köprü ve kemik tünel cerrahi teknikleri.

Genç ve atletik hastalarda geçirilmiş total menisektomi sonrası erken eklem dejenerasyonu gelişiminin engellenmesi için, semptomatik dönemin başlangıcında transplantasyon uygulanabilir. Ancak, yüksek aktivite düzeyi içeren spora dönüşte, başarılı fonksiyonel sonuçlar elde edilemeyebilir. ${ }^{[12]}$

\section{Kontrendikasyonlar}

Menisküs allogreft trasplantasyonu için kontrendikasyonları inceleyecek olursak, şu şekilde sıralayabiliriz:

1. Eklemde ileri evre yaygın kıkırdak hasarı (ICRS Evre 3 ve üzeri).

2. Femoral kondil morfolojisini bozacak değişiklikler ve osteofit formasyonun gelişmesi.

3. Aksiyel dizilim bozukluğu bulunması.

4. Diğer kontrendikasyonlar; obezite, iskelet immatüritesi, tedavi edilmemiş diz instabilitesi bulunması, sinoviyal hastalıkların bulunması, inflamatuvar artrit ve geçirilmiş eklem içi enfeksiyonlar. ${ }^{[13]}$

Yapılan literatür çalışmalarında kıkırdak dejenerasyonu, menisküs allogreft transplantasyonundan da başarılı sonuçlar alınabilmesi adına risk faktörü olarak gösterilmiştir. Ancak, erken evre ve ICRS Evre 3'ün altındaki kıkırdak dejenerasyonu bir risk faktörü olarak görülmemelidir. Ayrıca, eşlik eden lokalize kıkırdak defektleri transplantasyonla eş zamanlı olarak tedavi edilebilir. ${ }^{[14]}$
Sıklıkla 50 yaş üzerinde ve kıkırdak hasarı bulunan hastalar, transplantasyon için uygun değillerdir. Ancak, düzeltici osteotomiler uygulanması sonrası uygulanan transplantasyonlarda başarılı sonuçlar bildirilmiştir. ${ }^{[15]}$

\section{CERRAHI TEKNIK}

Günümüzde artroskopik menisküs transplantasyonu, oluşturduğu cerrahi morbidite ve ayrıca menisküs onarım tekniklerinin kolaylığı açısından açık cerrahi tekniklere göre belirgin olarak daha üstündür. 2013 yılında yapılan bir çalışmada, açık ve artroskopik menisküs allogreft transplantasyon yöntemleri karşılaştırılmış ve açık cerrahiler sonrası allogreftin radyal deplasmanının daha fazla olduğu görülmüş̧tür. ${ }^{[16]}$

Artroskopik işlem sırasında, öncelikle rutin olarak tanısal artroskopi uygulanarak eklem içindeki tüm kompartmanlar ayrıntılı olarak değerlendirilmelidir. Bu şekilde, eklem içi problemler incelenerek not edilmelidir.

Literatür incelendiğinde, allogreft tespiti uygulanırken izole yumuşak doku tespiti yerine kemik ve yumuşak doku tespitinin birlikte yapılmasının, eklem içi yük dağılımı açısından daha uygun olduğu gösterilmiştir. ${ }^{[17]}$

Meniskal allogreftler genel olarak iki teknik kullanılarak transplante edilebilir (Şekil 2). Bunlar, "kemik köprü" ve "kemik tünel” tekniği olarak isimlendirilmiştir. 


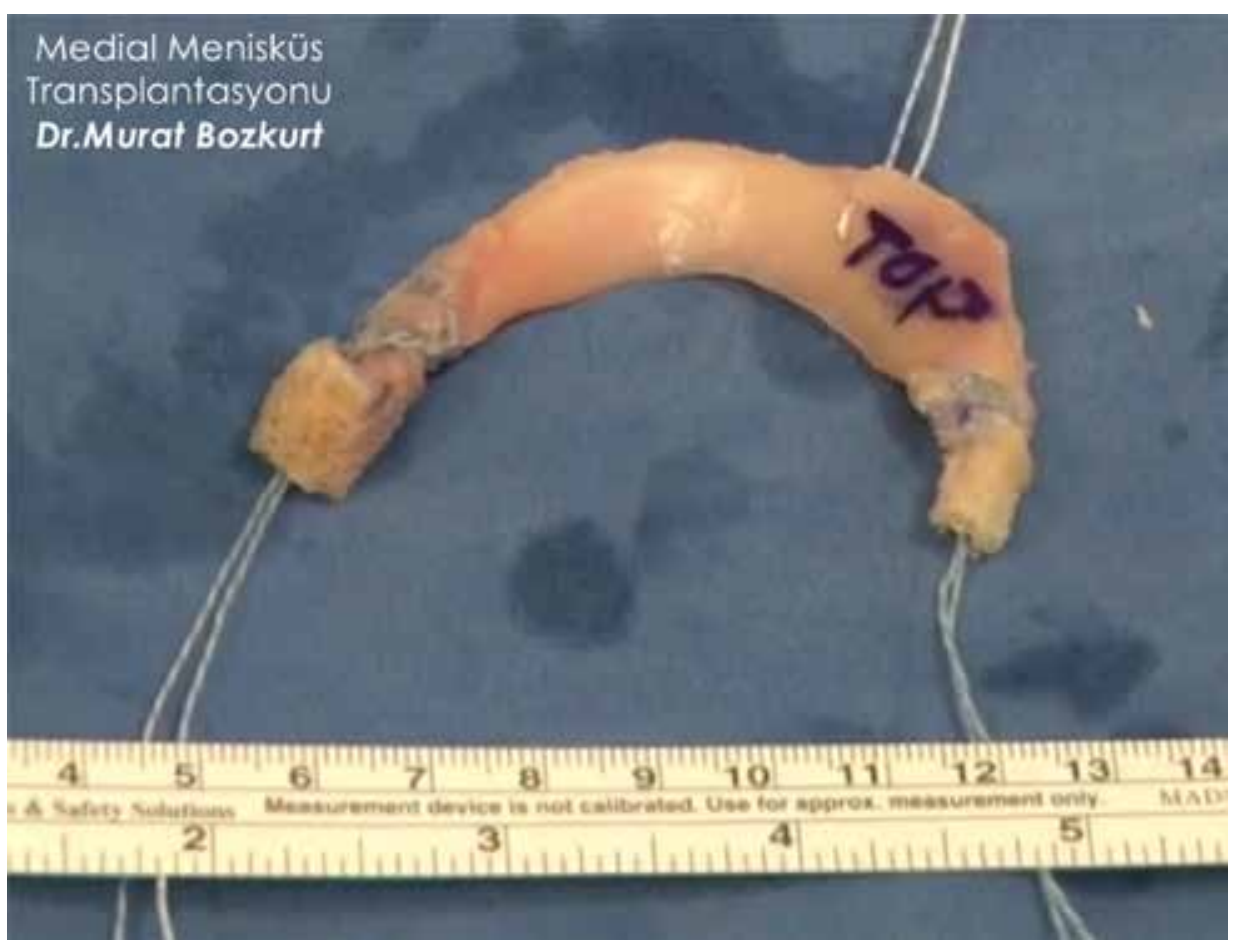

Şekil 3. Kemik tünel tekniği ile hazırlanan meniskal allogreft.

Her iki teknikte de ön ve arka boynuzların güvenli şekilde transplantasyonu amaçlanmıştır.

Kemik köprü tekniği ile, transplante edilecek menisküsün ön ve arka kökleri korunabilir. Bu teknik, mediyal ve lateral menisküs transplantasyonunun her ikisi için de uygulanabilir.

Kemik tünel tekniğinde, açılacak olan tünellerin mesafelerinin ayarlanması zordur. Ayrıca, lateral menisküsün ön-arka kökleri arasındaki kısa mesafe, açılacak tünellerin kesişmesi riskini taşır. Bu sebeple, kemik tünel tekniği mediyal menisküs trasplantasyonu için daha uygundur.

Allogreftin eklem içi redüksiyonu sırasında, yaklaşık $4 \mathrm{~cm}$ 'lik tibial tüberküle ve patellar tendona komşu anteromediyal artrotomi ve $3 \mathrm{~cm}$ 'lik vertikal posteromediyal insizyon genelde yeterlidir. ${ }^{[18]}$

Biz bu bölümde, mediyal menisküs allogreft tespitinde en sık tercih edilen, kemik tünel tespit metodundan bahsedeceğiz.

\section{Kemik Tünel}

Mediyal menisküs allogreftinin ön ve arka kökleri için, tibiada anatomik lokalizasyonun sağlandığı iki tünel açılır (Şekil 2). Bu işlem sırasında, ÖÇB tünellerini açmak için kullanılan kılavuzlar ve el aletlerinden yararlanılabilir. Allogreft üzerinde kemik tıkaçlar oluşturulmadan önce, greftin ön-arka kökleri işaret kalemi yardımı ile işaretlenmeli; ayrıca greftin üst ve alt yüzlerine de belirleyici işaretler konulmalıdır. Redüksiyon sonrası greftin uygun pozisyonu bu işaretlemeler ile kontrol edilebilir.

Ardından, allogreftin ön ve arka kök tıkaçlarının hazırlanmasına geçilir. Tibial platodan kök kısımları hariç serbestleştirilen menisküs allogreftinin ön ve arka kökleri, kesici motorlar ve el aletleri yardımı ile, tibial platoda açılan tünellere uyumlu tıkaçlar oluşturulacak şekilde kesilir (Şekil 3). Takiben, bu tıkaçlardan asıcı sütürler geçirilir. Bu asıcı sütürler greft redüksiyonu sırasında tibiada açılan tünellerin içinden geçirilerek tespit kolaylaştırılır. Ayrıca, allogreft üzerinden iki farklı traksiyon sütürü geçilir. Bunlardan ilki allogreftin ön-orta segmentinden geçilirken, ikincisi orta-arka segment hizasından geçilir. Bu traksiyon sütürleri de menisküsün mediyal hizalanmasını ve doğru yüzünün eklem içinde oturmasını sağlar. Bu teknik uygulanırken üç adet portal açılması gerekir. Bunlar; mediyal, lateral parapatellar ve posteromediyal portallerdir.

Hastaların eşlik eden ÖÇB yırtıkları varsa, rekonstrüksiyon sırasında kullanılacak tibial tüneller ile meniskal allogreft tıkaçların tünellerinin kesişme riski sebebiyle bu teknik uygun değildir. 


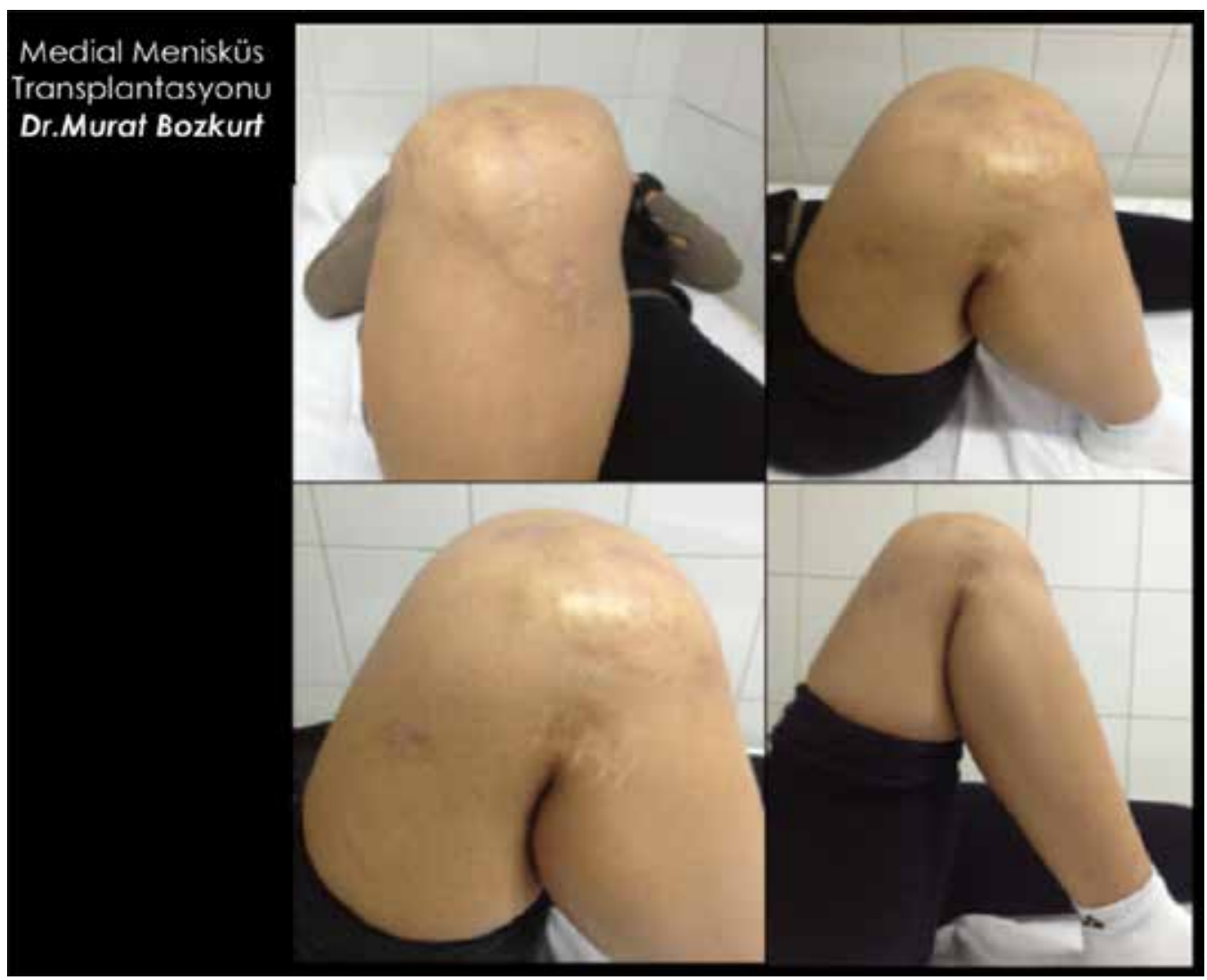

Şekil 4. Meniküs allogreft transplantasyonu sonrası rehabilitasyon programının tamamlanmasını takiben eklem hareket açıklığı.

Tibial tünellerin pozisyonlaması, doğru bir allogreft redüksiyonu için çok önemlidir. Arka kökün yerleştirileceği posterior tünel için, ÖÇB tibial tünel kılavuzu $45^{\circ}$ ye ayarlanır ve antero-posterior yönde açılır. Ön kökün yerleştirileceği anterior tünel için ise ÖÇB tibial tünel kılavuzu $60^{\circ}$ ye ayarlanır ve medio-lateral yönde açılır. Ardından, bu tünellerden asıcı sütürler ile posteromediyal bölgeden traksiyon yapıcı sütürler çekilir ve allogreft tünellere yerleştirilerek redüksiyon tamamlanmış olur. Daha sonra, allogreftin gövdesi yumuşak doku tespiti için her üç teknik de kullanılarak menisküs sütürasyonu yapılır ve tespit tamamlanmış olur. ${ }^{[19]}$

\section{REHABILITASYON}

Rehabilitasyon için ortak bir fikir birliği olmamakla birlikte, klinik deneyimlerimize göre hastalara dört haftalık üç dönem halinde toplamda 12 haftalık bir rehabilitasyon süreci uyguluyoruz.

Kemik tünellerin ve yumuşak dokulardaki iyileşmenin gerçekleşebilmesi için, ilk dört hafta ekstansiyonda kilitli açı ayarlı dizlikle, hastalara yük vermeden mobilizasyona başlıyoruz. Bu süreçte, hastaların kuadriseps güçlendirme egzersizleri uygulamalarının çok önemli olduğunu vurguluyoruz. Sonraki dört hafta içerisinde, kısmi yük vermeye başlayan hastalarımızın kilitli dizliklerini $0-90^{\circ}$ hareket açıklığına alarak, diz eklemine hareket veriyoruz. Rehabilitasyon sürecindeki son dört haftalık program içerisinde, hastaları kilitli dizlik olmadan tam diz hareketi ve tam yük vererek takip ediyoruz (Şekil 4).

Bu rehabilitasyon programı ile, hastaların ortalama 12. haftadan sonra yavaş tempoda düz koşuya başlaması ve 24 . haftadan sonra ise düşük aktivite düzeyinde spora dönüşleri mümkün olmaktadır.

\section{SONUÇ}

Genç hastalarda erken dönemde uygulanmış total veya subtotal menisektomiler sonrası eklem dejenerasyonunun ilerlememesi ve hayat kalitesinin arttırılmasına yönelik olarak, uygulanacak olan meniküs allogreft transplantasyonu oldukça faydalı bir tedavidir. Klinik 
çalışmalar, transplantasyon sonrası hastaların ağrılarının azaldığı ve günlük aktivite düzeylerinin arttığını destekler yöndedir.

Ancak bu, uzun bir öğrenme eğrisinin olması ve özellikle artroskopi destekli allogreft transplantasyon cerrahisi tekniğindeki zorluklar açısından tecrübeli cerrahlar tarafından uygulanması gereken bir prosedürdür. Ayrıca, hasta seçimi ve cerrahi sonrası rehabilitasyon süreci de başarıyı arttıran en önemli faktörler arasında gelmektedir.

Tüm bu zorlu süreç tek tek göz önünde bulundurulduğunda; genç erişkinlerde menisküs defektlerinin iyi tanınarak uygun cerrahi yöntemler ile tedavilerin gerçekleştirilmesi ve menisküslerin korunması, asıl dikkat edilmesi gereken noktadır. Doğal ve onarım sonrası iyileşmiş menisküs dokularının transplante menisküslerden daha iyi fonksiyonel ve biyomekanik sonuçlar vereceği unutulmamalıdır.

\section{KAYNAKLAR}

1. Kohn D, Moreno B. Meniscus insertion anatomy as a basis for meniscus replacement: a morphological cadaveric study. Arthroscopy 1995;11(1):96-103. Crossref

2. Fox AJ, Wanivenhaus F, Burge AJ, Warren RF, Rodeo SA. The human meniscus: a review of anatomy, function, injury, and advances in treatment. Clin Anat 2015;28(2):269-87. Crossref

3. Andrews S, Shrive N, Ronsky J. The shocking truth about meniscus. J Biomech 2011;44(16):2737-40. Crossref

4. DeHaven KE, Lohrer WA, Lovelock JE. Long-term results of open meniscal repair. Am J Sports Med 1995;23(5):524-30. Crossref

5. Cottrell JM, Scholten P, Wanich T, Warren RF, Wright TM, Maher SA. A new technique to measure the dynamic contact pressures on the Tibial Plateau. J Biomech 2008;41(10):23249. Crossref

6. Allen CR, Wong EK, Livesay GA, Sakane M, Fu FH, Woo SL. Importance of the medial meniscus in the anterior cruciate ligament-deficient knee. J Orthop Res 2000;18(1):109-15. Crossref
7. Fairbank TJ. Knee joint changes after meniscectomy. J Bone Joint Surg Br 1948;30B(4):664-70. Crossref

8. Johnson RJ, Kettelkamp DB, Clark W, Leaverton P. Factors effecting late results after meniscectomy. J Bone Joint Surg Am 1974;56(4):719-29. Crossref

9. Krause WR, Pope MH, Johnson RJ, Wilder DG. Mechanical changes in the knee after meniscectomy. J Bone Joint Surg Am 1976;58(5):599-604. Crossref

10. Levy IM, Torzilli PA, Warren RF. The effect of medial meniscectomy on anterior-posterior motion of the knee. J Bone Joint Surg Am 1982;64(6):883-8. Crossref

11. Alford W, Cole BJ. The indications and techinique for meniscal transplant. Orthop Clin North Am 2005;36(4):469-84. Crossref

12. van Arkel ER, de Boer $\mathrm{HH}$. Human meniscal transplantation. Preliminary results at 2 to 5-year follow-up. J Bone Joint Surg $\mathrm{Br}$ 1995;77(4):589-95. Crossref

13. Noyes FR, Barber-Westin SD. Meniscus transplantation: indications, techniques, clinical outcomes. Instr Course Lect 2005;54:341-53.

14. Cole BJ, Carter TR, Rodeo SA. Allograft meniscal transplantation: background, techniques, and results. Instr Course Lect 2003;52:383-96.

15. Noyes FR, Barber-Westin SD. Repair of complex and avascular meniscal tears and meniscal transplantation. J Bone Joint Surg Am 2010;92(4):1012-29.

16. De Coninck T, Huysse W, Verdonk R, Verstraete K, Verdonk P. Open versus arthroscopic meniscus allograft transplantation: magnetic resonance imaging study of meniscal radial displacement. Arthroscopy 2013;29(3):514-21. Crossref

17. Wang $\mathrm{H}$, Gee AO, Hutchinson ID, Stoner K, Warren RF, Chen TO, Maher SA. Bone Plug Versus Suture-Only Fixation of Meniscal Grafts: Effect on Joint Contact Mechanics During Simulated Gait. Am J Sports Med 2014;42(7):1682-9. Crossref

18. Peters G, Wirth $\mathrm{CJ}$. The current state of meniscal allograft transplantation and replacement. Knee 2003;10(1):19-31. Crossref

19. Beaufils P, Verdonk R, editors. The Meniscus. Part X: Meniscus Reconstruction -Allograft. Berlin Heidelberg: Springer-Verlag; 2010. p.303-63. Crossref 